\title{
FENOLOGIA DE TRÊS ESPÉCIES DE Myrsine L. EM FLORESTA SECUNDÁRIA SEMIDECÍDUA NO SUL DO BRASIL ${ }^{1}$
}

\begin{abstract}
Danielle Bauer ${ }^{2}$, Milena Nunes Bernardes Goetz ${ }^{3}$, Andressa Müller ${ }^{3}$ e Jairo Lizandro Schmitt ${ }^{4}$
RESUMO - Eventos vegetativos e reprodutivos de Myrsine lorentziana (Mez.) Arechav., M. guianensis (Aubl.) Kuntze e M. coriacea (Sw.) R. Br. foram avaliados por dois anos, em Floresta Estacional Semidecidual secundária, no Parque Municipal Henrique Luís Roessler, Novo Hamburgo, RS, Brasil. Os eventos fenológicos foram relacionados a variáveis climáticas, e observou-se correlação negativa com a temperatura e o fotoperíodo em M. guianensis e $M$. coriaceae, na fenofase floração, enquanto na frutificação essa correlação ocorreu em $M$. lorentziana e $M$. coriaceae. M. guianensis foi a única espécie que apresentou correlação negativa da fenofase de frutos maduros com o fotoperíodo e a temperatura. Floração e frutos maduros constituíram eventos sazonais nas três espécies, que em conjunto fornecem alimento para a avifauna durante o ano todo. A presença de frutos imaturos, queda foliar e brotamento demonstrou ser um evento contínuo ao longo do ano. Nenhum evento fenológico se correlacionou com a precipitação, resultado esperado em ambientes sem períodos secos regulares.
\end{abstract}

Palavras-chave: Aspectos fenológicos, Espécies arbóreas, Myrsinaceae e Floresta Atlântica.

\section{PHENOLOGY OF THREE SPECIES OF Myrsine L. IN A SECONDARY SEMIDECIDUOUS FOREST IN SOUTH OF BRAZIL}

\begin{abstract}
Vegetative and reproductive events of Myrsine lorentziana (Mez.) Arechav., M. guianensis (Aubl.) Kuntze and M. coriacea (Sw.) R. Br were evaluated for two years in a secondary semideciduous forest at the Parque Municipal Henrique Luis Roessler, Novo Hamburgo, RS, Brazil. Phenologic events were statistically correlated to climatic variables and a negative correlation of temperature and photoperiod with flowering in M. guianensis and M. coriaceae was found whereas in these two variables correlated positively in M. lorentziana and M. coriaceae fruiting. M. guianensis was the only species that showed a negative correlation of phenophase in ripen fruits with the photoperiod and temperature. Flowering and presence of ripen fruits were seasonal events for the three species, although altogether they were a year-round feeding resource for birds. The occurrence of green fruits, leaffall and leaf appearance seemed to be a continuous event throughout the year. Precipitation did not correlate with any phenologic event, which was expected in environments without regular dry periods.
\end{abstract}

Keywords: Atlantic Rain Forest, Myrsinaceae e Phenologic aspects of tree species.

\footnotetext{
${ }^{1}$ Recebido em 04.10.2011 aceito para publicação em 04.06.2012..

2 Prefeitura Municipal de Novo Hamburgo. E-mail: <daniellebauer@ig.com.br>.

${ }^{3}$ Universidade Feevale, Instituto de Ciências da Saúde, Laboratório de Botânica. E-mail: <milenabernardes@ yahoo.com.br> e $<$ dessamuller@terra.com.br>.

${ }^{4}$ Universidade Feevale, Instituto de Ciências da Saúde. E-mail: <jairols@ feevale.br>.
} 


\section{INTRODUÇÃO}

A fenologia avalia a ocorrência de eventos biológicos periódicos e sua relação com fatores bióticos e abióticos locais, assim como a relação entre as fases destes eventos, dentro de uma mesma espécie ou entre várias (VAN SCHAIK et al., 1993; MORELLATO, 2003; LIETH, 1974). Os estudos fenológicos realizados com plantas têm sua importância na compreensão da dinâmica dos ecossistemas florestais e no entendimento dos mecanismos de reprodução e de regeneração das espécies (CHAPMAN et al., 1999; TALORA; MORELLATO, 2000; MANTOVANI et al., 2003).

A densidade e permanência de dada população numa comunidade dependem da sua capacidade de autorregeneração e de fatores extrínsecos como clima, interações bióticas e disponibilidade de luz (DORNELES; NEGRELLE, 2000). Assim, ao fornecer dados para estabelecer o período em que recursos como frutos, sementes, folhas, flores vão estar disponíveis a dispersores, herbívoros e polinizadores ao longo do ano (ALENCAR et al., 1979; BARBOSA et al., 2009), os estudos fenológicos estão contribuindo para aumentar a compreensão das relações ecológicas entre as diferentes espécies.

Ciclos fenológicos e mudanças nos seus padrões podem ser influenciados pelos efeitos da radiação, precipitação e temperatura. O surgimento de flores em florestas tropicais coincide com o aumento do fotoperíodo e a diminuição da precipitação, enquanto a produção de frutos geralmente se concentra na estação chuvosa (ALENCAR et al., 1979; SUN et al., 1996). Nas regiões subtropicais, como o sul do Brasil, estudos apontam uma relação maior dos eventos fenológicos com a temperatura e com o fotoperíodo (MARQUES; OLIVEIRA, 2004; MARQUES et al., 2004; MARCHIORETTO et al., 2007).

Os padrões fenológicos de plantas nos variados ecossistemas podem ser diversificados, dependendo em que nível (comunidade, população, indivíduo) são analisados (NEWSTROM et al., 1994; WILLIAMS et al., 1999). Sun et al. (1996) destacaram a importância de se procederem a análises em níveis hierárquicos mais baixos para melhor compreensão dos diferentes padrões fenológicos. San Martin-Gajardo e Morellato (2003) sugeriram que estudos dos fatores que podem influenciar as fenofases de plantas em florestas com baixa sazonalidade, em níveis populacional e individual, são interessantes para o estabelecimento de relações de causa e efeito da fenologia. Na última década, no Brasil meridional, entre os estudos fenológicos, incluindo até 10 espécies arbóreas, podem-se citar os trabalhos de Bencke e Morellato (2002), Pedroni et al. (2002), San Martin-Gajardo e Morellato (2003), Mantovani et al. (2004), Lopes e Buzato (2005) e Nunes et al. (2008) na Região Sudeste e de Bianchini et al. (2006), Alberti e Morellato (2008) e Marchioretto et al. (2007) na Região Sul.

Myrsine L. possui vários representantes arbóreos e tem distribuição pantropical, com ocorrência de 26 espécies no Brasil (FREITAS; CARRIJO, 2010). Espécies arbóreas destacam-se nos processos naturais de sucessão (DORNELES; NEGRELLE, 2000), e muitas têm seus frutos consumidos e dispersos pela avifauna (PINESCHI, 1990; SIQUEIRA, 1993). Foram avaliados os eventos fenológicos apresentados por M. coriacea (Sw.) R. Br., M. guianensis (Aubl.) Kuntze e M. lorentziana (Mez.) Arechav. em Floresta Estacional Semidecídual, no Parque Municipal Henrique Luís Roessler (PMHLR), RS, Brasil; discutidas suas relações com as condições climáticas locais; e avaliada sua importância como fontes de alimento para a avifauna, dada a existência de número considerável de aves frugívoras e onívoras na área (FRANZ et al., 2010).

\section{MATERIAL E MÉTODOS}

Área de estudo - O trabalho foi realizado em formação secundária de floresta semidecídua, localizada no Parque Municipal Henrique Luís Roessler - PMHLR ( $29^{\circ} 41^{\prime}$ S e $51^{\circ} 06^{\prime}$ W), Município de Novo Hamburgo, RS, Brasil. Aárea do parque foi incluída no Sistema Estadual de Unidades de Conservação - SEUC pela Lei Estadual n 4.129, de 21 de dezembro de 2009. O PMHLR apresenta extensão de 54,4 ha, distribuídos entre campo, áreas úmidas e floresta secundária (WEISHEIMER et al., 1996). O clima regional é do tipo Cfa, segundo a classificação de Köppen, ou seja, subtropical úmido sem período seco. Segundo dados da Estação Meteorológica de Campo Bom (RS), nos últimos 20 anos a temperatura média foi de $19,5^{\circ} \mathrm{C}$ e a pluviosidade média, $1.649,5 \mathrm{~mm}$. O solo é constituído de muita argila e misturado com areia fina e grande quantidade de matéria orgânica, apresenta coloração marrom-avermelhada e estava pouco compactado (WEISHEIMER et al., 1996), sendo classificado como Planossolo Hidromórfico eutrófico arênico (STRECK et al., 2002). 
Método amostral - Ao longo de $1.300 \mathrm{~m}$ de uma trilha preexistente no PMHLR, foram amostrados os indivíduos de Myrsine guianensis, $M$. coreacea e $M$. lorentziana, que apresentavam no mínimo $10 \mathrm{~cm}$ de diâmetro à altura do peito (DAP), localizados no máximo a $5 \mathrm{~m}$ de distância da borda. As plantas foram marcadas com etiquetas numeradas e monitoradas, mensalmente, durante o período de julho de 2008 a junho de 2009 , denominado como o primeiro ano; e de julho de 2009 a junho de 2010, constituindo o segundo ano. O número de indivíduos de cada espécie variou de nove a 19 , estando acima dos valores mínimos propostos por Fournier e Charpantier (1975). O material botânico coletado foi depositado no Herbarium Anchieta (PACA), da Universidade do Vale do Rio dos Sinos, em São Leopoldo, RS. As fenofases observadas foram floração, frutificação, queda foliar (QF) e brotamento (BRO). Para a construção das curvas fenológicas, dividiu-se a floração em início de floração (botões) (IF) e antese (AN) e, a frutificação, em frutos imaturos (FI) e maduros (FM) (MORELLATO et al., 1989).

Dados climáticos - Os dados climatológicos utilizados no estudo foram obtidos na Estação

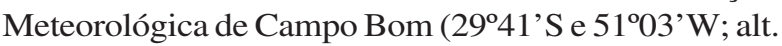
$25,8 \mathrm{~m}$ ). O fotoperíodo foi proveniente do anuário interativo do Observatório Nacional (ON) disponível em: <http://euler.on.br/ephemeris/index.php>.

Análise estatística - A sincronia entre os indivíduos de cada espécie para as fenofases foi verificada através do índice de sincronia (Z) adaptado de Augspurger (1983) por Pedroni et al. (2002). Em cada espécie, a frequência mensal relativa de indivíduos em cada fenofase foi relacionada à precipitação, temperatura e fotoperíodo, por meio do teste de correlação de postos de Spearman $\left(\mathrm{r}_{\mathrm{s}}\right)$, adotando-se nível de significância de 5\% e utilizando o programa estatístico SPSS versão16.0. Os valores de referência que qualificam as correlações foram adotados de acordo com Davis (1971). Para a análise estatística circular, os meses foram convertidos em ângulos, em que cada dia correspondeu a $0,9836^{\circ}$, num total de $340,27^{\circ}$ no $1^{\circ}$ ano de amostragem e $336,32^{\circ}$ no $2^{\circ}$. Foi calculada em ângulos a frequência de ocorrência de cada espécie nas diferentes fenofases, e obtiveram-se os seguintes parâmetros: o ângulo médio $(\mu)$ e sua conversão para data média do evento; o vetor $r$, que é a medida da concentração de indivíduos em torno do ângulo médio (valores entre 0-1); e o limite de confiabilidade (teste de Rayleigh) para cada variável fenológica. Os cálculos foram realizados no software ORIANA (KOVACH, 2009).

\section{RESULTADOS}

Dados climáticos - A maior média de temperatura foi observada no mês de fevereiro em ambos os anos de observação $\left(24,5-25,9^{\circ} \mathrm{C}\right)$ e a menor média, em junho $\left(12,8^{\circ} \mathrm{C}\right)$ do primeiro ano de amostragem e em julho $\left(11,2^{\circ} \mathrm{C}\right)$ do segundo. A precipitação anual foi menor no primeiro $(1.375,9 \mathrm{~mm})$ do que no segundo ano (2.244,8 mm). A duração dos dias variou de 10,27 h a 14,02 h, nos 24 meses (Figura 1).

Queda foliar e brotamento - As respectivas fenofases vegetativas ocorreram continuamente ao longo dos dois anos, nas três espécies estudadas, sem que algum indivíduo permanecesse períodos com a copa totalmente desfolhada. A maioria dos indivíduos monitorados renovou as folhas simultaneamente, refletindo em índices de sincronia $(Z)$ próximos de 1 em todas as espécies. Não houve correlação entre a fenofase de brotamento e fatores climáticos em nenhuma das espécies monitoradas. A concentração de indivíduos em torno das datas médias (r) dos dois eventos foi baixa durante todo o período de amostragem, e não foi possível estimar a data média dos dois eventos de todas as espécies (Tabela 1).

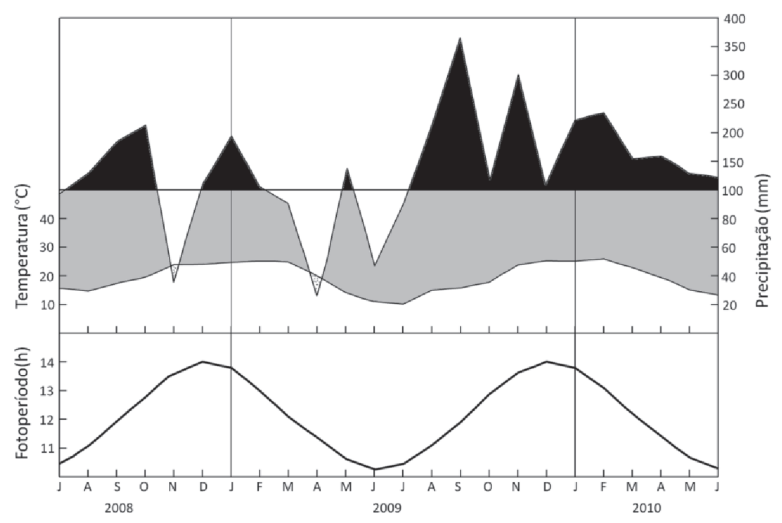

Figura 1 - Média mensal de fotoperíodo e climatograma do período de julho de 2008 a junho de 2010 , no Parque Municipal Henrique Luís Roessler, Novo Hamburgo, RS, Brasil.

Figure 1 -Average monthly photoperiod and meteorological diagram from July 2008 to June 2010 at the Parque Municipal Henrique Luís Roessler, Novo Hamburgo, RS, Brazil.

Revista Árvore, Viçosa-MG, v.36, n.5, p.859-868, 2012

Arvore, Vicosa-MG, v.36, n.5, p.859-868, 2012

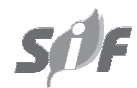


Tabela 1 - Resultados da análise estatística circular das variáveis fenológicas dos indivíduos de Myrsine lorentziana (Mez.) Arechav., M. guianensis (Aubl.) Kuntze e M. coreacea (Sw.) R. Br. de julho de 2008 a junho de 2010.

Table 1 - Results of the circular statistical analysis for phenological data of Myrsine lorentziana (Mez.) Arechav., M. guianensis (Aubl.) Kuntze and M. coreacea (Sw.) R. Br individuals from July 2008 to June 2010.

\begin{tabular}{|c|c|c|c|c|c|c|c|}
\hline & \multicolumn{7}{|c|}{ Variáveis fenológicas } \\
\hline & Ano & Botão floral & Antese & Frutos imaturos & Frutos maduros & Queda foliar & Brotação \\
\hline & & \multicolumn{6}{|c|}{ Myrsine lorentziana } \\
\hline \multirow[t]{2}{*}{ Média do vetor $(\mu)$} & 1 & $\begin{array}{l}278,21^{\circ} \\
\text { (19 Abr.) }\end{array}$ & $\begin{array}{c}301,54^{\circ} \\
\text { (13 Mai.) }\end{array}$ & $\begin{array}{c}76,52^{\circ} \\
(30 \text { Set.) }\end{array}$ & $\begin{array}{l}168,22^{\circ} \\
(28 \mathrm{Dez} .)\end{array}$ & $\begin{array}{l}253,88^{\circ} \\
(5 \mathrm{Ju} 1 .)\end{array}$ & $\begin{array}{c}337,65^{\circ} \\
\text { (18 Jun.) }\end{array}$ \\
\hline & 2 & $\begin{array}{l}274,36^{\circ} \\
(18 \mathrm{Abr} .)\end{array}$ & $\begin{array}{l}286,99^{\circ} \\
(1 \text { Mai. })\end{array}$ & $\begin{array}{l}53,37^{\circ} \\
(4 \text { Set.) }\end{array}$ & $\begin{array}{l}148,05^{\circ} \\
(9 \text { Dez. })\end{array}$ & $\begin{array}{l}357,80^{\circ} \\
(12 \mathrm{Jul} .)\end{array}$ & $311,33^{\circ}$ \\
\hline \multirow{2}{*}{$\begin{array}{l}\text { Comprimento do } \\
\text { vetor médio }(r)\end{array}$} & & & & & & & \\
\hline & $\begin{array}{l}1 \\
2\end{array}$ & $\begin{array}{l}0,90 \\
085\end{array}$ & $\begin{array}{l}0,94 \\
0,90\end{array}$ & $\begin{array}{l}0,41 \\
0.24\end{array}$ & $\begin{array}{l}0,61 \\
0,72\end{array}$ & $\begin{array}{l}0,17 \\
0,16\end{array}$ & $\begin{array}{c}0,05 \\
0\end{array}$ \\
\hline \multirow[t]{3}{*}{ Teste de Rayleigh (P) } & 1 & $<0,001$ & $<0,001$ & $<0,001$ & $<0,001$ & $<0,001$ & $<0,05$ \\
\hline & 2 & $<0,001$ & $<0,001$ & $<0,001$ & $<0,001$ & $<0,001$ & $0,919^{\mathrm{NS}}$ \\
\hline & & \multicolumn{6}{|c|}{ Myrsine coreacea } \\
\hline \multirow[t]{2}{*}{ Média do vetor $(\mu)$} & 1 & $\begin{array}{l}282,27^{\circ} \\
(24 \mathrm{Abr} .)\end{array}$ & $\begin{array}{l}338,05^{\circ} \\
\text { (18 Jun.) }\end{array}$ & $\begin{array}{l}72,04^{\circ} \\
(22 \text { Set.) }\end{array}$ & $\begin{array}{l}142,98^{\circ} \\
(3 \text { Dez.) }\end{array}$ & $343,60^{\circ}$ & $\begin{array}{l}337,65^{\circ} \\
\text { (18 Jun.) }\end{array}$ \\
\hline & 2 & $\begin{array}{l}300,09^{\circ} \\
(14 \text { Mai.) }\end{array}$ & $\begin{array}{l}311,29^{\circ} \\
\text { (26 Jun.) }\end{array}$ & $\begin{array}{l}69,57^{\circ} \\
\text { (21 Set.) }\end{array}$ & $\begin{array}{l}114,55^{\circ} \\
(5 \text { Nov. })\end{array}$ & $\begin{array}{l}340,96^{\circ} \\
\text { (25 Jun.) }\end{array}$ & $271,28^{\circ}$ \\
\hline \multirow[t]{2}{*}{$\begin{array}{l}\text { Comprimento do vetor } \\
\text { médio (r) }\end{array}$} & 1 & 0,52 & 0,60 & 0,59 & 0,79 & 0,04 & 0,05 \\
\hline & 2 & 0,89 & 0,87 & 0,47 & 0,97 & 0,11 & 0,01 \\
\hline \multirow[t]{3}{*}{ Teste de Rayleigh (P) } & 1 & $<0,001$ & $<0,001$ & $<0,001$ & $<0,001$ & $0,091 \mathrm{NS}$ & $<0,05$ \\
\hline & 2 & $<0,001$ & $<0,001$ & $<0,001$ & $<0,001$ & $<0,001$ & $0,746^{\mathrm{NS}}$ \\
\hline & & \multicolumn{6}{|c|}{ Myrsine guianensis } \\
\hline \multirow[t]{2}{*}{ Média do vetor $(\mu)$} & 1 & $\begin{array}{l}344,18^{\circ} \\
\text { (25 Jun.) }\end{array}$ & $\begin{array}{l}340,27^{\circ} \\
\text { (22 Jun.) }\end{array}$ & $11,28^{\circ}$ & $\begin{array}{l}353,74^{\circ} \\
(28 \mathrm{Jul} .)\end{array}$ & $\begin{array}{l}353,74^{\circ} \\
(27 \mathrm{Jul} .)\end{array}$ & $\begin{array}{l}346,97^{\circ} \\
(28 \mathrm{Jul} .)\end{array}$ \\
\hline & 2 & $\begin{array}{l}325,68^{\circ} \\
\text { (9 Jun.) }\end{array}$ & $\begin{array}{l}300,87^{\circ} \\
(15 \text { Mai.) }\end{array}$ & $298,73^{\circ}$ & $\begin{array}{l}340,09^{\circ} \\
\text { (24 Jun.) }\end{array}$ & $115,00^{\circ}$ & $337,80^{\circ}$ \\
\hline \multirow[t]{2}{*}{$\begin{array}{l}\text { Comprimento do vetor } \\
\text { médio }(r)\end{array}$} & 1 & 0,99 & 1 & 0,06 & 0,51 & 0,05 & 0,05 \\
\hline & 2 & 0,92 & 0,98 & 0,01 & 0,66 & 0,01 & 0 \\
\hline \multirow[t]{2}{*}{ Teste de Rayleigh (P) } & 1 & $<0,001$ & $<0,001$ & $0,085^{\mathrm{NS}}$ & $<0,001$ & $0,06^{\mathrm{NS}}$ & 0,02 \\
\hline & 2 & $<0,001$ & $<0,001$ & $0,879^{\mathrm{NS}}$ & $<0,001$ & $0,912^{\mathrm{NS}}$ & $0,9^{\mathrm{NS}}$ \\
\hline
\end{tabular}

A queda foliar apresentou valores de frequência mensal relativa variando entre 10 e $100 \%$ nas três espécies analisadas. Myrsine lorentziana apresentou maior frequência de indivíduos, perdendo as folhas entre os meses de março e outubro (80 a 100\%), com índices de sincronia de 0,9 e 0,8 no $1^{\circ}$ e no $2^{\circ}$ ano, respectivamente (Figura 2). M. coriacea teve de 90 a $100 \%$ dos indivíduos nessa fenofase no primeiro ano e de 50 a $100 \%$ no segundo, refletindo em uma sincronia alta $(Z=0,9)$ no primeiro e no segundo período de observação $(\mathrm{Z}=0,8)$. M. guianensis apresentou frequência bastante variada de indivíduos com queda foliar (10 a 100\%) e o mesmo índice de sincronia $(\mathrm{Z}=0,8)$ nos dois anos de monitoramento. Com exceção de M. guianensis, a queda foliar correlacionou-se negativamente com o fotoperíodo e com a temperatura, e na população de $M$. lorentziana essa relação foi evidenciada nos dois anos de amostragem (fotoperíodo: $r_{s}=-0,70 ; p=0,01 ; r_{s}=-0,68 ; p=0,01 ; e$ temperatura: $r_{s}=-0,72$; $\mathrm{p}<0,01 ; \mathrm{r}_{\mathrm{s}}=-0,73 ; \mathrm{p}<0,01,1^{\circ}$ e $2^{\circ}$ anos, respectivamente), enquanto na população de $M$. coreaceae, apenas no $2^{\circ}$ ano (fotoperíodo: $r_{s}=-0,79 ; p<0,01$; e temperatura: $\left.r_{s}=-0,79 ; p<0,01\right)$. A precipitação não influenciou esse evento fenológico, durante o período estudado.

Floração - O aparecimento de botões florais em Myrsine lorentziana ocorreu uma vez em cada ano, iniciando no final do verão (março) e se estendendo até o início do inverno (junho), com maior frequência

Revista Árvore, Viçosa-MG, v.36, n.5, p.859-868, 2012 
entre março e abril (65-95\%). No segundo ano, essa fenofase foi mais curta, encerrando-se em maio (Figura 2). A sincronia dessa fenofase foi alta, variando de 0,6 ( $2^{\circ}$ ano) a 0,7 ( $1^{\circ}$ ano), e não houve sua correlação com os fatores climáticos. A floração plena (antese) apresentou seu pico nos meses de abril e maio no primeiro ano (50-60\%); e em abril, no segundo ano (85\%), sendo a sincronia anual baixa $(\mathrm{Z}=0,4)$, durante todo o período. Não houve correlação dessa fenofase com os fatores climáticos. A concentração de indivíduos em torno das datas médias (r) em ambas as fenofases foi alta em todo o período, e a data média de cada evento fenológico situou-se em abril para botões florais e maio para flores abertas (Tabela 1).
Na população de Myrsine coreacea, os botões florais também apareceram uma vez por ano, a partir do verão (janeiro) até o inverno (julho), mas com frequência máxima (90-100\%) no outono, entre abril e maio, nos dois anos (Figura 2). No segundo ano, os botões surgiram mais tarde (março), finalizando em junho. A sincronia dessa fenofase foi baixa no primeiro $(Z=0,4)$ e alta no segundo período $(Z=0,8)$. No $1^{\circ}$ ano, essa fenofase correlacionou-se negativamente com o fotoperíodo $\left(r_{s}=-0,70 ; p=0,01\right)$. O pico de floração plena dessa população concentrou-se em maio, durante todo o período $(100 \%)$, também com sincronia elevada no $2^{\circ}(Z=0,8)$ e baixa no $1^{\circ}$ ano $(Z=0,2)$. Esse evento fenológico demonstrou correlação negativa com

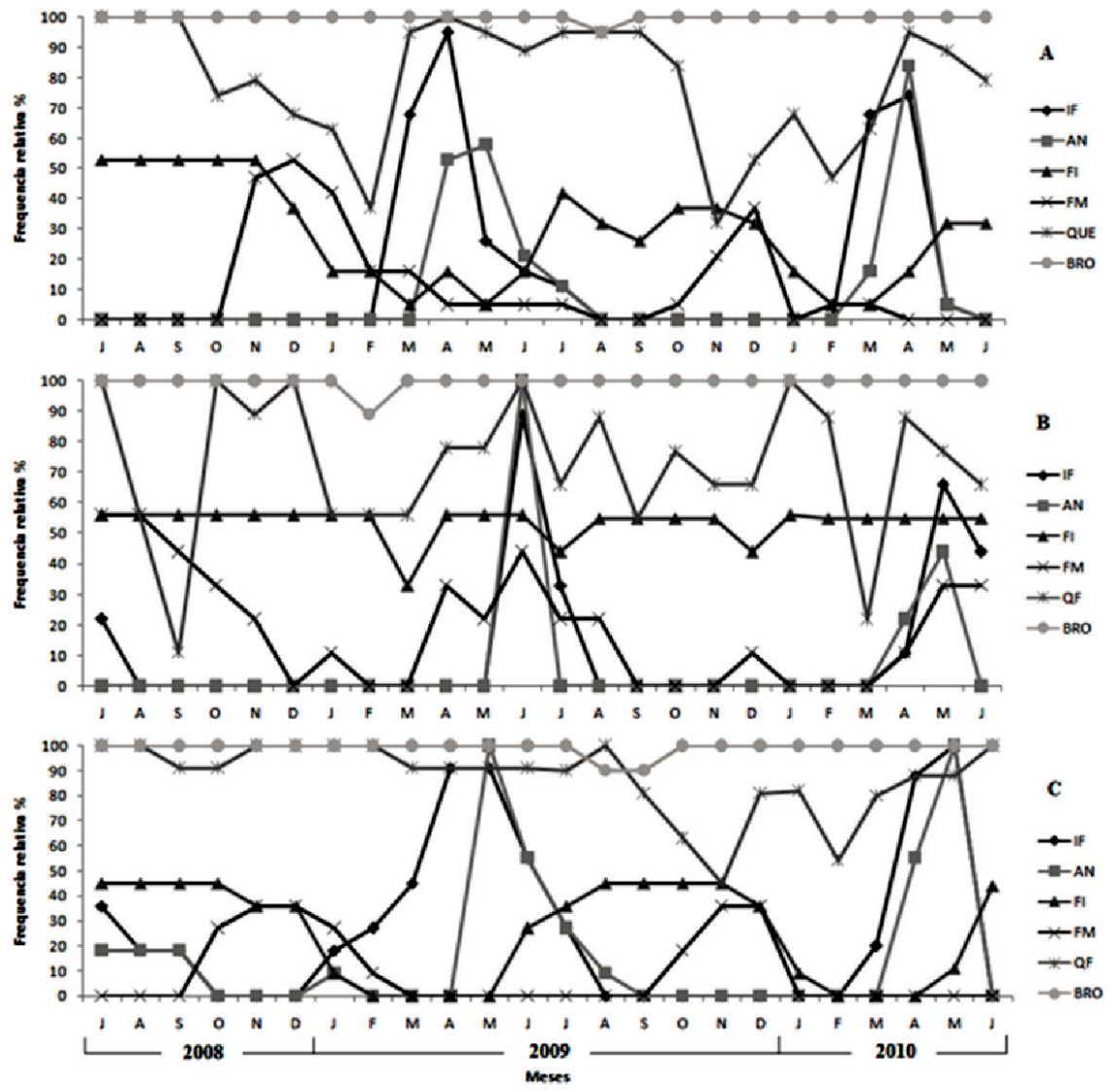

Figura 2 - Frequência relativa (\%) de indivíduos de Myrsine lorentziana (Mez.) Arechav. (A), M. guianensis (Aubl.) Kuntze (B) e M. coreacea (Sw.) R. Br. (C), de julho de 2008 a junho de 2010, nas fenofases: IF-Início de Floração, AN-Antese, FI-Frutos Imaturos, FM-Frutos Maduros, QF-Queda Foliar e BRO-Brotamento.

Figure 2 - Relative frequency (\%) of Myrsine lorentziana (Mez.) Arechav. (A), M. guianensis (Aubl.) Kuntze (B) and M. coreacea (Sw.) R. Br. (C) individuals from July 2008 to June 2010 in phenophase: IF-Early Flowering, ANAnthesis, FI-green Fruit, FM-ripen Fruit, QF- Leaf Fall and BRO-Leaf Appearance. 
fotoperíodo $\left(r_{s}=-0,73 ; p<0,01 ; r_{s}=-0,60 ; p=0,04,1^{\circ}\right.$ e $2^{\circ}$ anos, respectivamente). Houve correlação negativa também com a temperatura $\left(r_{s}=-0,72 ; p<0,01\right)$, no primeiro ano. A concentração de indivíduos em torno das datas médias (r) de ambas as fenofases foi maior no $2^{\circ}$ ano de amostragem. A data média para botões florais situou-se em abril no $1^{\circ}$ ano e maio no $2^{\circ}$ ano, enquanto para o evento flores abertas a data média ficou em junho (Tabela 1).

No $1^{\circ}$ ano de amostragem, os botões florais nos indivíduos de Myrsine guianensis surgiram no inverno (junho-julho), com pico de maior frequência em junho (90\%). No $2^{\circ}$ ano, a fenofase iniciou mais cedo (abril) e estendeu-se até junho, com pico em maio (70\%) (Figura 2). A sincronia na população foi elevada no $1^{\circ}$ ano $(Z=0,6)$ e baixa no $2^{\circ}(Z=0,3)$. Esse evento fenológico foi influenciado negativamente pelo fotoperíodo $\left(r_{s}=-0,65 ; p=0,02 ; r_{s}=-0,78 ; p<0,01,1^{\circ}\right.$ e $2^{\circ}$ anos, respectivamente). No segundo ano, houve correlação negativa da fenofase também com a temperatura $\left(r_{\mathrm{s}}=-0,63 ; \mathrm{p}=0,03\right)$. A frequência máxima de indivíduos em floração plena foi registrada em junho no $1^{\circ}$ ano $(100 \%)$ e em maio no $2^{\circ}(40 \%)$. A sincronia foi máxima no $1^{\circ}$ período $(Z=1)$ e muito baixa no $2^{\circ}(Z=0,1)$. Nenhum evento reprodutivo demonstrou relação com os fatores climáticos analisados. A data média $(\mu)$ para o evento botão floral situou-se em junho, enquanto para flores abertas ocorreu a antecipação da data no $2^{\circ}$ ano (maio) em relação ao $1^{\circ}$ (junho), com alta concentração de indivíduos (Tabela 1).

Frutificação - A frutificação compreendeu desde os frutos imaturos (verdes) até maduros (coloração roxa). Embora com frequência bastante variável (5-50\%), foram observados na população de Myrsine lorentziana indivíduos com frutos imaturos durante todo o período, com maior frequência entre julho e novembro (30-50\%), refletindo em baixa sincronia nos dois anos $(Z=0,2$ e $\mathrm{Z}=0,1)$. Não houve correlação dessa fenofase com fatores climáticos. Indivíduos com frutos maduros apresentaram maior frequência em dezembro (35-50\%), com a fenofase iniciando em novembro (primavera) e estendendo-se até junho (inverno), no primeiro ano. No segundo ano, o período foi mais curto, apenas de outubro (primavera) a março, no final do verão (Figura 2). Houve correlação positiva da fenofase no $1^{\circ}$ ano, com a temperatura $\left(r_{s}=0,70\right.$; $\mathrm{p}=0,01)$ e com o fotoperíodo $\left(\mathrm{r}_{\mathrm{s}}=0,77 ; \mathrm{p}<0,01\right)$. A concentração de indivíduos em torno das datas médias (r) para frutos imaturos foi baixa em todo o período, enquanto para

Revista Árvore, Viçosa-MG, v.36, n.5, p.859-868, 2012 frutos maduros foi alta no mesmo período. As datas médias localizaram-se em setembro para frutos imaturos e em dezembro para frutos maduros (Tabela 1).

Na população de Myrsine coreacea, a ocorrência de indivíduos com frutos imaturos foi de julho (inverno) a janeiro (verão). No entanto, os picos do primeiro ano ocorreram entre julho e outubro (45\%) e entre agosto e novembro (45\%) no segundo ano (Figura 2). A espécie apresentou baixa sincronia em todo o período $(Z=0,1)$ e nenhuma relação com os fatores climáticos. O pico de indivíduos com frutos maduros concentrou-se entre novembro e dezembro (35\%), mas estendeu-se de outubro a fevereiro no $1^{\circ}$ ano e de outubro a dezembro no $2^{\circ}$ (Figura 2). Houve correlação positiva com fotoperíodo $\operatorname{nos}$ dois $\operatorname{anos}\left(\mathrm{r}_{\mathrm{s}}=0,87 ; \mathrm{p}<0,01 ; \mathrm{r}_{\mathrm{s}}=0,61 ; \mathrm{p}=0,03\right.$, respectivamente) e positiva com temperatura apenas no primeiro ano $\left(r_{s}=0,70 ; p=0,02\right)$. As datas médias $(\mu)$ dos eventos localizaram-se em setembro para frutos imaturos, com concentração baixa de indivíduos. Para frutos maduros, a data média ficou em dezembro no $1^{\circ}$ ano e em novembro no $2^{\circ}$, com alta concentração de indivíduos (Tabela 1).

Myrsine guianensis apresentou frequência de $30-55 \%$ em frutos imaturos durante os 24 meses de amostragem, sem um período nem pico definido (Figura 2). O sincronismo dos indivíduos foi baixo no biênio $(Z=0,2)$, e a fenofase correlacionou-se positivamente com a precipitação no $2^{\circ}$ ano $\left(r_{s}=0,65\right.$; $\mathrm{p}=0,02)$. A presença de indivíduos com frutos maduros foi praticamente contínua ao longo do estudo com apenas dois picos de frequência no inverno do $1^{\circ}$ ano, em julhoagosto (55\%), e do $2^{\circ}$ ano, em maio-junho (30\%) (Figura 2). A correlação da frequência de indivíduos foi negativa com a temperatura $\left(r_{s}=-0,88 ; p<0,01 ; r_{s}=-0,71 ; p=0,01\right.$, $1^{\circ}$ e $2^{\circ}$ anos, respectivamente) e com o fotoperíodo $\left(r_{s}=-0,73 ; p<0,01 ; r_{s}=-0,74 ; p<0,01,1^{\circ}\right.$ e $2^{\circ}$ anos, respectivamente). Em frutos maduros, a data média ( $\mu$ ) ficou em julho no $1^{\circ}$ ano e em junho no $2^{\circ}$ ano, com média concentração de indivíduos (Tabela 1).

A sincronia dos indivíduos (Z) para a maturação dos frutos na população das três espécies foi baixa, variando de zero a 0,2 , durante os 24 meses.

\section{DISCUSSÃO}

As três espécies de Myrsine não apresentaram padrão de queda foliar e brotamento sazonal, sendo esses eventos vegetativos contínuos durante o período

\footnotetext{
Revista Árvore, Viçosa-MG, v.36, n.5, p.859-868, 2012
} 
amostrado, refletindo em elevado sincronismo anual e em baixa concentração de indivíduos em torno da data média estimada. Comportamento semelhante para a queda foliar foi observado por Talora e Morellato (2000) em M. coriaceae e M. umbellata em floresta superúmida de São Paulo; por Marques e Oliveira (2004) em M. venosa A. DC. em floresta atlântica do Paraná; e por Bencke (2005) em M. umbellata em floresta semidecídua no Rio Grande do Sul.

Em Myrsine lorentziana e $M$. coriaceae, a diminuição do fotoperíodo e da temperatura parece estimular a abscisão das folhas. O brotamento demonstrou ser pouco influenciado pelas variáveis climáticas, relacionando-se com a elevação da temperatura apenas em $M$. coriaceae. Em M. guianensis, esses fatores climáticos não influenciaram os eventos fenológicos vegetativos. Marchioretto et al. (2007) observaram relação negativa do brotamento com temperatura e fotoperíodo em M. umbellata, em uma floresta psamófila do Rio Grande do Sul.

Seghieri et al. (1995) sugeriram que, em casos em que a mudança foliar (brotação e queda) é um evento contínuo, a dependência da precipitação torna-se menor, tal como observado neste estudo. A queda foliar tem sido relacionada ao estresse hídrico em florestas tropicais sazonais (BORCHERT, 1983; PEDRONI et al., 2002), enquanto o brotamento, por sua vez, é relacionado ao fim do período mais seco nessas florestas (PEDRONI et al., 2002). A falta de sazonalidade em relação à ocorrência dessas fenofases pode estar relacionada à ausência de períodos secos regulares na região estudada. Fatores endógenos próprios de cada espécie (BORCHERT, 1983) podem também ter influenciado a queda e brotamento nas três espécies de Myrsine.

Floração - Das três espécies estudadas, Myrsine coriaceae e $M$. guianensis demonstraram tendência a iniciar a floração em meses com menor disponibilidade de luz. A antese ocorreu entre o outono e o inverno nas três espécies, porém apenas $M$. coriaceae teve esse evento reprodutivo relacionado com temperatura e fotoperíodo. No entanto, essa influência climática sobre a espécie não pode ser confirmada, principalmente em decorrência da ausência de correlação com a temperatura no $2^{\circ}$ ano de amostragem. O sincronismo dos indivíduos tendeu a ser elevado, bem como a concentração em torno das datas médias, sugerindo que essas duas fenofases sejam eventos sazonais nessas espécies. Athayde et al. (2009) observaram padrão sazonal na floração em $M$. lorentziana e $M$. loefgrenii (Mez) Imkhan. em uma floresta ribeirinha do Rio Grande do Sul, bem como Marques e Oliveira (2004) em $M$. venosa.

Além de fatores climáticos, o comportamento da floração em espécies tropicais deve ser explicado como resultado da influência de fatores climáticos, edáficos e bióticos (BORCHET, 1983). Talora e Morellato (2000) sugeriram que a polinização deve ter papel fundamental na regulação da época de floração das espécies.

Frutificação - As três espécies apresentaram em comum o padrão individual heterogêneo para frutos imaturos, refletindo em baixa sincronia anual. A ocorrência de frutos imaturos caracterizou-se como evento não sazonal, praticamente constante ao longo do ano nas três espécies de Myrsine, exceto em M. coriaceae, que apresentou essa fenofase no outono do $1^{\circ}$ ano e no inverno do $2^{\circ}$, com a concentração de indivíduos maior em torno da data média estimada. A fenofase não apresentou relação com os fatores climáticos, pois a correlação entre frutos imaturos e a precipitação observada em M. guianensis foi um evento isolado que pode estar condicionado por outras variáveis não analisadas neste estudo.

O período de ocorrência de frutos maduros apresentou-se diferenciado nas espécies, mas a concentração em torno das datas médias foi alta, sugerindo que essa fenofase também seja sazonal. Myrsine lorentziana e $M$. coriaceae concentraram a fenofase de frutificação nos meses mais quentes e com maior insolação, tal como observado por Athayde et al. (2009) na primeira espécie e em M. loefgrenii. Embora M. guianensis tenha apresentado frutos maduros praticamente o ano todo, essa fenofase ocorreu mais intensamente no inverno, demonstrando relação negativa com fotoperíodo e temperatura. Jung-Mendaçolli et al. (2005), estudando as espécies de Myrsinaceae no Estado de São Paulo, observaram floração e frutificação durante o ano todo em $M$. guianensis e $M$. coriaceae. Em M. lorentziana, a frutificação ocorreu entre a primavera e o início do outono, período semelhante ao encontrado na área de estudo. Em florestas sazonais, a época de frutificação está relacionada ao tipo de fruto e à síndrome de dispersão. Frutos anemocóricos geralmente frutificam na estação mais seca, enquanto os frutos zoocóricos amadurecem no início da estação mais úmida (MORELLATO et al., 1989). A ocorrência de frutificação durante o ano todo sugere que ambientes com ausência de períodos secos oferecem condições

Revista Árvore, Viçosa-MG, v.36, n.5, p.859-868, 2012 
pouco restritivas para o contínuo desenvolvimento e amadurecimento de frutos (TALORA; MORELLATO, 2000).

Esses resultados corroboram a hipótese de que na ausência de estresse hídrico fatores como a temperatura e o fotoperíodo parecem influenciar mais a frutificação. Alvim (1964) propôs que a relação da fenologia de plantas tropicais com o fotoperíodo tende a ser maior à medida que ocorre o distanciamento da região equatorial.

Nas três espécies, a fenofase fruto imaturo destacou-se por apresentar os picos mais longos do evento (5-12 meses), baixa frequência relativa (30$50 \%$ ) e assincronia. A floração (botões e antese) caracterizou-se por apresentar os picos dos eventos mais curtos (dois meses) entre as demais fenofases, uma frequência relativa em geral alta (40-100\%) e sincronia entre os indivíduos. Esse comportamento na floração pode servir como estratégia para concentrar a presença de polinizadores sazonais (MARQUIS, 1988; VAN SCHAIK et al., 1993). As espécies de Myrsine são pioneiras em áreas de regeneração, e seus frutos necessitam ser ingeridos por aves para viabilizar a germinação (PINESCHI, 1990; SIQUEIRA, 1993). A produção contínua de frutos dispersos por animais tem sido associada frequentemente a uma estratégia para a manutenção de recursos aos animais dispersores de sementes (SNOW, 1965; HILTY, 1980; CONCEIÇÃO et al., 2007).

\section{CONCLUSÕES}

Em nenhuma das espécies estudadas as fenofases de brotamento e queda foliar se relacionaram com a precipitação, demonstrando que essa variável não é fator decisivo nesses eventos, bem como nas demais fenofases. Essa baixa relação justifica-se pelo fato de que, no clima local, as chuvas estão bem distribuídas ao longo do ano, não havendo períodos de seca pronunciados. Pelo padrão da fenologia vegetativa, constatou-se que as três espécies são perenifólias.

De modo geral, percebeu-se similaridade no comportamento fenológico entre $M$. lorentziana, $M$. coriaceae e M. guianensis, porém esta última se diferenciou das demais pela fenologia dos frutos maduros, concentrados no período do inverno, e pela

Revista Árvore, Viçosa-MG, v.36, n.5, p.859-868, 2012 relação negativa desse evento com a temperatura e o fotoperíodo. Isso indica desencadeamento da maturação pela diminuição da radiação e da temperatura (inverno), enquanto nas duas primeiras espécies essa fenofase é influenciada pelo aumento dessas variáveis climáticas.

Pelos dados de frutificação encontrados, as três espécies fornecem, em conjunto, alimento para a avifauna local durante praticamente todo o ano, estabelecendo-se, assim, como importante fonte alimentar em todas as estações do ano.

\section{AGRADECIMENTOS}

À Universidade Feevale e à Fundação de Amparo à Pesquisa do Estado do Rio Grande do Sul (FAPERGS), pela concessão da bolsa de Iniciação Científica à segunda e à terceira autora, respectivamente; e à direção do PMHLR, pela autorização da realização do estudo nesta unidade de conservação.

\section{REFERÊNCIAS}

ALBERTI, L. F.; MORELLATO, L. P. C. Influência da abertura de trilhas antrópicas e clareiras naturais na fenologia reprodutiva de Gymnanthes concolor Spreng (Euphorbiaceae). Revista Brasileira de Botânica, v.31, n.1, p.53-59, 2008.

ALENCAR, J. C. A.; ALMEIDA, R. A.; FERNANDES, N. P. Fenologia de espécies florestais em floresta tropical úmida de terra firme na Amazônia Central. Acta Amazônica, v.9, n.1, p.163-198, 1979.

ALVIM, P. T. Periodicidade do crescimento das árvores em climas tropicais. In: CONGRESSO NACIONAL DE BOTÂNICA, 1964, Porto Alegre. Anais... Porto Alegre: UFRGS, 1964. p.405-422.

ATHAYDE, E. A. et al. Fenologia de espécies arbóreas em uma floresta ribeirinha em Santa Maria, sul do Brasil. Revista Brasileira de Biociências, v.7, n.1, p.43-51, 2009.

AUGSPURGER, C. K.; FRANSON, S. E. Input of wind-dispersed seeds into lightgaps and forest sites in neotropical forest. Journal of Tropical Ecology, v.4, n.1, p.239-252, 1983.

Revista Arvore, Viçosa-MG, v.36, n.5, p.859-868, 2012 
BARBOSA, J. M. et al. Ecologia da dispersão de sementes em florestas tropicais. In: MARTINS, S. V. Ecologia de florestas tropicais do Brasil.. Viçosa, MG: Universidade Federal de Viçosa, 2009. p.52-73.

BENCKE, C. S. C.; MORELLATO, L. P. C. Estudo comparativo da fenologia de nove espécies arbóreas em três tipos de floresta atlântica no sudeste do Brasil. Revista Brasileira de Botânica, v.25, n.2, p.237-248. 2002.

BENCKE, C. S. C. Estudo da fenologia de espécies arbóreas em uma floresta semidecídua no Parque Estadual de Itapuã, Viamão, RS. 2005. 65f. Tese (Doutorado em Ecologia) - Universidade Federal do Rio Grande do Sul, Porto Alegre, 2005.

BIANCHINI, E.; PIMENTA, J. A.; SANTOS, F. A. M. Fenologia de Chrysophyllum gonocarpum (Mart. e Eichler) Engl. (Sapotaceae) em floresta semidecídua do Sul do Brasil. Revista Brasileira de Botânica, v.29, n.4, p.595-602, 2006.

BORCHERT, R. Phenology and control of flowering in tropical trees. Biotropica, v.15, p.81-89, 1983.

CHAPMAN, C. A. et al. Fruit and flower phenology at two sites in Kibale National Park, Uganda. Journal of Tropical Ecology, v.15, p.189-211. 1999.

CONCEIÇÃO, A. A.; FUNCH, L. S.; PIRANI, J. R. Reproductive phenology, pollination and seed dispersal syndromes on sandstone outcrop vegetation in the "Chapada Diamantina", northeastern Brazil: population and community analyses. Revista Brasileira de Botânica, v.30, n.3, p.475-485. 2007.

DAVIS, J. A. Elementary survey analysis. Englewood: Prentice-Hall, 1971. 206p.

DORNELES, L. P. P.; NEGRELLE, R. R. B.

Aspectos da regeneração natural de espécies arbóreas da Floresta Atlântica. Iheringia, Série Botânica, v.53, p.85-100. 2000.

FOURNIER, L. A.; CHARPANTIER, C. El tamaño de la muestra y la frequencia de las observaciones en el estudio de las caracteristicas fenológicas de los arbores tropicales.

Turrialba, v.25, n.1, p.45-48, 1975.
FRANZ, I.; CAPPELATTI, L.; BARROS, M. P. Bird community in a florest patch isolated by the urban matrix at the Sinos River Basin, Rio Grande do Sul State, Brazil, with comments on the possible local defaunation. Brazilian Journal of Biology, v.70, n.4, p.1137-1148, 2010.

FREITAS, M. F.; CARRIJO, T. T. Myrsine In: Lista de Espécies da Flora do Brasil. Rio de Janeiro: Jardim Botânico do Rio de Janeiro, 2010. (http://floradobrasil.jbrj.gov.br/2010/FB010223).

HILTY, S. L. Flowering and fruiting periodicity in a premontane rain forest in Pacific Colombia. Biotropica, v.12, p.298-306. 1980.

JUNG-MENDAÇOLLI, S. L.; BERNACCI, L. C.; FREITAS, M. F. Myrsinaceae. In: WANDERLEY, M. G. L. et al (eds.). Flora Fanerogâmica do estado de São Paulo. São Paulo: Rima, 2005. v.4. p.279-300.

KOVACH, W. L. Oriana - Circular Statistics for Windows. Version 3. Pentraeth, Wales: Kovach Computing Services, 2009.

LIETH, H. Introduction to phenology and modeling of seasonality. In: LIETH, H. (Ed.). Phenology and seasonality modeling. New York: Springer Verlag, 1974. p.3-19.

LOPES, L. E.; BUZATO, S. Biologia reprodutiva de Psychotria suterella Muell. Arg. (Rubiaceae) e a abordagem de escalas ecológicas para a fenologia de floração e frutificação. Revista Brasileira de Botânica, v.28, n.4, p.785-795, 2005.

MANTOVANI, M. et al. Fenologia reprodutiva de espécies arbóreas de formações secundárias da Mata Atlântica. Revista Árvore, v.27, n.4, p.451-458, 2003.

MANTOVANI, A.; MORELLATO, L. P. C.; REIS, M. S. Fenologia reprodutiva e produção de sementes em Araucaria angustifolia (Bert.) O. Kuntze. Revista brasileira de Botânica, v.27, n.4, p.787-796, 2004.

MARCHIORETTO, M. A.; MAUHS, J.; BUDKE, J. C. Fenologia de espécies arbóreas zoocóricas em uma floresta psamófila no sul do Brasil. Acta Botanica Brasilica, v. 21, p.193-201. 2007.

Revista Árvore, Viçosa-MG, v.36, n.5, p.859-868, 2012 
MARQUES, M. C. M.; OLIVEIRA, P. E. A. M. Fenologia de espécies do dossel e do sub-bosque de duas Florestas de Restinga na Ilha do Mel, sul do Brasil. Revista brasileira de Botânica, v.27, n.4, p.713-723. 2004.

MARQUIS, R. J. Phenological variation in the Neotropical understory shrub Piper arieianum: causes and consequences. Ecology, v.69, n.5, p.1552-1565, 1988.

MARQUES, M.C.M.; Roper, J.J.; SALVALAGGIO, A.P.B. 2004. Phenological patterns among plant life forms in a subtropical forest in Southern Brazil. Plant Ecology, 173:203-213.

MORELLATO, L. P. C. et al. Estudo comparativo da fenologia de espécies arbóreas de floresta de altitude e floresta mesófila semidecídua na Serra do Japi, Jundiaí, São Paulo. Revista Brasileira de Botânica, v.12, n.1, p.85-98, 1989.

MORELLATO, L. P. C. Phenological data, networks, and research: South America. In SCHWARTZ, M. D. (Org). Phenology: an integrative environmental science. Dordrecht: Kluwer Academic Publishers, 2003. p.75-92.

NEWSTROM, L. E.; FRANKIE, G. W.; BAKER, H. G. A new classification for plant phenology based on flowering patterns in lowland tropical rain forest at La Selva, Costa Rica. Biotropica, v.26, p.141-159, 1994.

NUNES, Y. R. F. et al. Aspectos ecológicos da aroeira (Myracrodruon urundeuva Allemão - Anacardiaceae): fenologia e germinação de sementes. Revista Árvore, v.32, n.2, p.233-243. 2008.

OBSERVATÓRIO NACIONAL (ON). Disponível em: <http://euler.on.br/ephemeris/index.php>. Acesso em: 01 de julho. 2010.

PEDRONI, F.; MARYLAND, S.; SANTOS F. A. M. Fenologia da copaíba (Copaifera langsdorffii Desf. - Leguminosae, Caesalpinioideae) em uma floresta semidecídua no sudoeste do Brasil. Revista Brasileira de Botânica, v.25, n.2, p.183-194. 2002.

Revista Árvore, Viçosa-MG, v.36, n.5, p.859-868, 2012
PINESCHI, R. B. Aves como dispersores de sete espécies de Rapanea (Myrsinaceae) no maciço do Itatiaia, estados do Rio de Janeiro e Minas Gerais. Ararajuba, v.1, n.1, p.73-78, 1990.

SAN MARTIN-GAJARDO, I.; MORELLATO, L. P. C. Fenologia de Rubiaceae do sub-bosque em floresta Atlântica no sudeste do Brasil. Revista Brasileira de Botânica, v.26, n.3, p.299-309, 2003.

SEGHIERI, J.; FLORET, C. H.; PONTANIER, R. Plant phenology in relation to water availibility: herbaceous and woody species in the savannas of northern Cameroon. Journal of Tropical Ecology, v.11, n.2, p.237-254, 1995.

SIQUEIRA, J. C. O gênero Rapanea Aublet (Myrsinaceae) na região serrana do estado do Rio de Janeiro: aspectos taxonômicos e ecológicos das espécies. Pesquisas Série Botânica, v. 44, n.1, p.41-52, 1993.

SNOW, D. W. A possible selective factor in the evolution of fruiting seasons in tropical forest. Oikos, v.15, n.2, p.274-281, 1965.

STRECK, E. V. et al. Solos do Rio Grande do Sul. Porto Alegre: Universidade Federal do Rio Grande do Sul, 2002.

SUN, C. et al. Tree phenology in a tropical montane forest in Rwanda. Biotropica, v.28, n.4b, p.668-681, 1996.

TALORA, D. C.; MORELlATO, P. C. Fenologia de espécies arbóreas em floresta de planície litorânea do sudeste do Brasil. Revista Brasileira de Botânica, v.23, n.1, p.13-26, 2000.

VAN SCHAIK, C. P.; TERBORGH, J. W.; WRIGHT, S. J. The phenology of tropical forests: adaptative significance and consequences for primary consumers. Annual Review of Ecology and Systematics, v.24, p.353-377, 1993.

WEISHEIMER, C.; MAUHS, J.; SAUL, A. F. P. Plano de Manejo - Parque Municipal Henrique Luís Roessler - Parcão. Novo Hamburgo: Prefeitura Municipal de Novo Hamburgo, 1996. 31p.

WILLIAMS, R. J. et al. Reproductive phenology of woody species in a North Australian Tropical savanna. Biotropica, v.31, n.4, p.626-636, 1999. 